\title{
Problems assessing uptake of Huntington disease predictive testing and a proposed solution
}

\author{
Roslyn J Tassicker ${ }^{1}$, Betty Teltscher ${ }^{2}, \mathrm{M}_{\text {Kaye } \text { Trembath }^{3} \text {, Veronica Collins }}{ }^{3,4}$, \\ Leslie J Sheffield ${ }^{1,4,5}$, Edmond Chiu ${ }^{2}$, Lyle Gurrin ${ }^{6}$ and Martin B Delatycki ${ }^{\star}, 1,3,4,5$
}

${ }^{1}$ Genetic Health Services Victoria, Parkville, Victoria, Australia; ${ }^{2}$ University of Melbourne, Huntington Disease Clinic, St George's Hospital, Melbourne, Australia; ${ }^{3}$ Bruce Lefroy Centre for Genetic Health Research, Parkville, Victoria, Australia; ${ }^{4}$ Murdoch Childrens Research Institute, Parkville, Victoria, Australia; ${ }^{5}$ Department of Pediatrics, University of Melbourne, Melbourne, Australia; ${ }^{6}$ Centre for Molecular, Environmental, Genetic and Analytic Epidemiology, School of Population Health, University of Melbourne, Melbourne, Australia

The uptake of predictive testing for Huntington disease informs our understanding of decision making by those at risk and assists with planning for service provision. Uptake figures have been reported from several centers based on the total number of people who have undertaken predictive testing as a percentage of those estimated to be at $50 \%$ risk in the region. This method produced a figure of $35 \%$ from our own service, much higher than observation of the local pedigrees indicated, and higher than other published reports. We have identified some errors in the commonly used formula. The major errors are the use of the cumulative total of those who have had testing with a static denominator of those at $50 \%$ risk, and the failure to exclude from the at-risk group those who are too young and therefore ineligible to test. We report data from the Huntington Disease Register of Victoria and estimate the prevalence to be 8 per 100000 in 1999. Additional data on individuals at risk were collated. We found that for every diagnosed person there were 4.2 individuals at $50 \%$ risk, a lower ratio than one to five hypothesized in the literature. We examined these ratios in the context of uptake.Significantly, we provide a solution to the calculation of uptake with a formula that factors in a dynamic denominator and corrects for the number of years testing has been offered. Using this formula, we calculated an uptake of $13.0-15.4 \%$ for the state of Victoria, Australia. This formula can be used to compare uptake across different centers.

European Journal of Human Genetics (2009) 17, 66-70; doi:10.1038/ejhg.2008.142; published online 30 July 2008

Keywords: Huntington disease; uptake; prevalence; predictive testing

\section{Introduction}

Predictive testing for Huntington disease (HD) has been available by linkage analysis since the late 1980s and direct mutation detection since 1993. The uptake of predictive testing for HD is a focus of interest for those involved with

${ }^{*}$ Correspondence: Associate Professor MB Delatycki, Genetic Health Services Victoria, 10th Floor, Royal Childrens Hospital, Flemington Road, Parkville, Victoria 3052, Australia.

Tel: +61 38341 6284; Fax: + 6138341 6390;

E-mail: martin.delatycki@ghsv.org.au

Received 25 October 2007; revised 5 May 2008; accepted 2 July 2008; published online 30 July 2008 clinical practice and has been reported in a number of studies (Table 1). Uptake has generally been calculated from the number of individuals who have had predictive testing as a proportion of the number estimated to be at risk in the population, expressed as a percentage.

Applying this formula to data from our center, uptake at the end of 1999 was 24\%, and in 2004 it was 35\%. This proportion was higher than the observations made by the HD Counsellor working with families attending this center, which is the sole service provider for a large geographical area. ${ }^{10}$ This prompted examination of the uptake formula used in other studies. 
Table 1 Summary of reports on uptake

\begin{tabular}{|c|c|c|c|c|}
\hline Author, year & Countries & $\begin{array}{l}\text { Reported estimated } \\
\text { prevalence of } \\
\text { Huntington disease }\end{array}$ & $\begin{array}{l}\text { Total individuals estimated } \\
\text { at } 50 \% \text { risk; (ratio, basis) }\end{array}$ & $\begin{array}{l}\text { Reported uptake (reporting } \\
\text { period, total years }{ }^{\mathrm{a}} \text { ) }\end{array}$ \\
\hline Taylor $1994^{1}$ & Australia & $5-6: 100000$ & 5730; (1:5, Conneally $\left.{ }^{2}\right)$ & $5.5 \%$ (1987-1993, 6 years) \\
\hline Maat-Kievit et $a l^{4 \mathrm{~b}}$ & The Netherlands & $\begin{array}{l}\text { 6.5:100 } 000 \text { based on } \\
\text { Leiden roster; also gives } \\
4: 10000 \text { European } \\
\text { prevalence }\end{array}$ & $\begin{array}{l}\text { 3115; (from Leiden roster; } \\
\text { comparable with 1:5, } \\
\text { Conneally }^{2} \text { ) }\end{array}$ & $\begin{array}{l}24 \% \text { based on the number } \\
\text { at risk from the roster, or } \\
25 \% \text { using } 1: 5^{2} \\
\text { (1987-1997, } 10 \text { years) }\end{array}$ \\
\hline Harper et $\left.a\right|^{5}$ & United Kingdom & $7.5: 100000$ & $\begin{array}{l}15000\left(1: 5 \text { Conneally }^{2}\right) \text { and } \\
\text { then those aged }<15 \text { and } \\
>64 \text { years were excluded } \\
\text { based on census data }\end{array}$ & $\begin{array}{l}18 \% \text { of those aged } 15-64 \\
(1987-1997,10 \text { years) }\end{array}$ \\
\hline Goizet et $a l^{6}$ & France & $5: 100000$ & 9000 (refers to Harper ${ }^{5}$ ) & $\begin{array}{l}5 \% \text { tested }(1993-2000, \\
7 \text { years })\end{array}$ \\
\hline Creighton et $a l^{\mathrm{cc}}$ & Canada & $8.4: 100000$ & $\begin{array}{l}\text { Prevalence based (and refers } \\
\text { to Conneally }{ }^{2} \text { ) }\end{array}$ & $\begin{array}{l}18 \%(1987-2000,13 \\
\text { years); also gives annual } \\
\text { uptake, range } 1.5-2.9 \%\end{array}$ \\
\hline
\end{tabular}

Wording and uptake percentages are those given by authors of the studies.

${ }^{a}$ As some data collection periods did not extend for the entire calendar year, the reported total years is also given here.

${ }^{b}$ Includes data from an earlier study by Tibben et al. ${ }^{8}$

'Includes data from a pilot study by Bloch et al. ${ }^{9}$

\section{The conventional method of calculating uptake}

Table 1 summarizes published uptake reports. Most authors have used the prevalence of HD in the country or region as a basis to then estimate those at 50\% risk of HD, using a ratio of one symptomatic individual to five individuals at $50 \%$ risk. ${ }^{1,4,5,7}$ It is unclear how this figure was reached in two of the studies. ${ }^{3,6}$ To calculate uptake, all authors have then taken the total number of individuals who have completed predictive testing from the time testing was first offered at their center, as a proportion of those at risk, and expressed this proportion as a percentage.

Two early studies ${ }^{8,9}$ (not shown in Table 1 , as later studies incorporated these data) appear to be the first to use this calculation. These two studies do not use the term uptake but report on candidates and applicants currently in their testing programs as a proportion of those at risk. An English report, ${ }^{11}$ which is the first to use the term uptake in relation to predictive HD testing, is a descriptive paper on clients known to their testing program, a subgroup of those at risk. These early studies do not report on those who have specifically completed testing so are not comparable and therefore not included in Table 1.

Although prevalence of HD is estimated and reported in regions (Table 1), it is problematic determining the size of the group at $50 \%$ risk. To estimate this group, Conneally ${ }^{2}$ proposed a theoretical ratio of one symptomatic individual to five individuals at $50 \%$ risk, based on the observation that an individual who develops HD will be symptomatic for approximately one-third of his/her life. Thus, for every symptomatic individual, there will be two who are gene positive but presymptomatic; and for every gene positive individual, he reasoned, there will be another person who is gene negative. The ratio of 1:5 has become an accepted convention. ${ }^{1,4,5,7}$

\section{Problems identified with the conventional method of calculating uptake}

Use of a cumulative total of those who have tested while the figure used for those at risk remains static A major problem we have identified with the accepted methodology for calculating uptake, is the use of the cumulative total of those who have undertaken predictive testing. This is clearly dependant on the number of years the service has been offered. The problem can be seen in Table 1 with a reported uptake figure of 3\% over 4 years from Laccone et al, ${ }^{3}$ which contrasts with an uptake of $24 \%$ over 10 years from that of Maat-Kievit et al. ${ }^{4}$ Using the accepted uptake formula, the uptake through our genetic service was $24 \%$ in 1999 and $35 \%$ by 2004 . At the current rate of testing, by the year 2034 we can project that uptake will be greater than $100 \%$, an obvious absurdity.

The numerator used by the authors in Table 1 is a dynamic figure, being the total (cumulative) number of individuals at $50 \%$ risk who have completed predictive testing. We have clarified, above, that the time periods in the studies vary significantly, ranging from 2 to 13 years, and that the numerator increases the longer the period of the study.

The denominator used by the authors has been a static number, being the estimated number of individuals at 50\% risk of $\mathrm{HD}$ at a single point in time. This figure will be a relative constant over time as it has been based on a point prevalence of symptomatic HD in that region. However, 
the individual members who comprise the group at 50\% risk over the study period will, in fact, increase - or cumulate - over time.

If a cumulative numerator is used, then to accurately assess uptake, a cumulative denominator must also be used. Individuals in the designated region within the study period will have become at risk and joined the pool of potential testees over that same period. It is only by using a cumulative denominator that an accurate uptake can be calculated.

Restated, an uptake calculation needs to incorporate all those who have tested (numerator) as a proportion, expressed as a percentage, of all those who could have tested (denominator) for the nominated period.

\section{Eligibility for testing by age}

A second problem identified relating to the calculation of uptake is eligibility for testing by age. Only data of those eligible to access predictive testing are valid for use in an uptake calculation. Predictive testing protocols specify that only those who have attained the age of majority are eligible to access predictive testing. ${ }^{12}$ Calculation of the number of individuals at 50\% risk of HD without excluding those who are too young to test is invalid. Harper et al took age into account in reporting uptake but other studies summarized in Table 1 do not.

In 1999, examining data from the Huntington Disease Register of Victoria (see below), individuals in Victoria aged 19 years and below $(n=78)$ represented $5.6 \%$ of the group at $50 \%$ risk (Figure 1), and most of this subgroup would not qualify to test by age. Although the age of majority in this state is 18 years, the data were not available from the Register to provide for this more precise percentage calculation.

\section{Estimation of the size of the group at $50 \%$ risk}

An important factor requiring clarification in an uptake calculation is the method of determining the number of individuals at $50 \%$ risk of $\mathrm{HD}$ in a particular region. Most estimates $^{1,4,5,7}$ have used Conneally's 1:5 (symptomatic: at $50 \%$ risk) ratio to determine this figure. The accuracy of this ratio is therefore important to obtain an accurate estimate of uptake of the predictive test. We examined
Conneally's ratio with reference to empirical data from this region.

The Huntington Disease Register of Victoria was initiated in the 1950s and regularly maintained from the 1970s by two of the present authors (EC and BT) at a centralized HD clinic. Ascertainment of all cases of HD in the state of Victoria was undertaken at the end of 1999 (BT and RT). At that time, there were 329-339 individuals with a diagnosis of HD known to the Register. The uncertainty regarding 10 individuals was due to changes in access to formal death notification. The averaged figure (334 individuals) is used in the remainder of this paper.

An additional data source for the ascertainment was the sole DNA laboratory undertaking HD genetic testing for the state and included all individuals symptomatically confirmed from 1993 to 1999 (inclusive). There were 48 individuals who had been confirmed by DNA analysis who were not known to the Register. It is not known if any of these 48 had died between the time of diagnosis and the end of 1999.

In total, 382 individuals had a diagnosis of HD at the end of 1999 . The population of Victoria in 1999 was reported as $4736000^{13}$ giving a prevalence of HD of 8.0 per 100000 .

The Register also held information on those at risk of HD. Individuals were defined as being at 50\% risk if a parent had HD. Data on those at risk of HD did not have the methodological rigor of neurological examination to confirm asymptomatic status of the individuals. Some information was provided by family members and, in some instances, may have been several years old. Despite the limitations, the information is still valuable to this discussion.

The Register indicated that there was a total of 1391 individuals at 50\% risk of HD at the end of 1999, shown in Figure 1. Individuals known to the Register to be diagnosed with $\mathrm{HD}$ at the same time was $334(88.8 \%$ of the total cohort diagnosed with HD). The observed ratio was therefore one diagnosed individual to 4.2 at $50 \%$ risk (1:4.2), which differs from the theoretical ratio of 1:5. By contrast, empirical data reported from the The Netherlands is very similar to Conneally's 1:5 ratio. ${ }^{4}$

A further factor that also requires clarification in an uptake calculation is exclusion of those who have tested at $25 \%$ risk or with a presymptomatic (gene positive) parent.

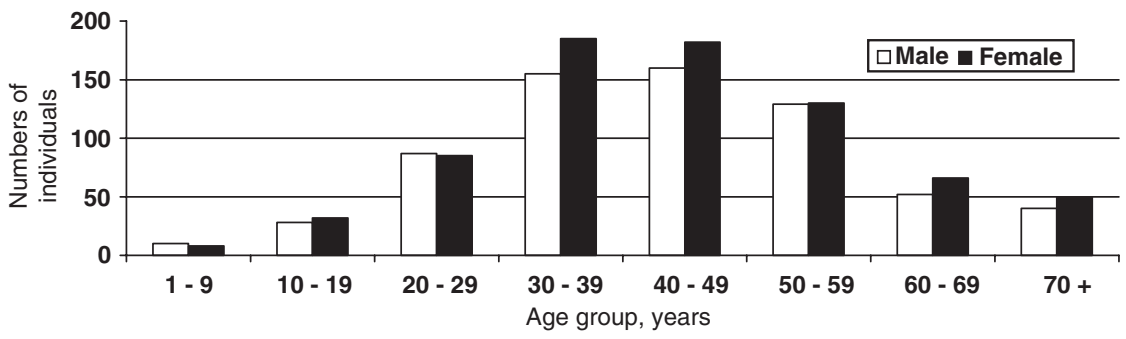

Figure 1 Individuals grouped by age (years) and gender at 50\% risk of Huntington disease, Victoria, 1999. 
Although these individuals are eligible for predictive testing, for the purposes of calculating uptake, the criterion of a parent with symptomatic HD determines that an individual is at $50 \%$ risk. This criterion needs to be consistently applied in an uptake calculation.

\section{A proposed solution}

One way to accurately estimate the uptake of predictive testing for HD would be to establish a cohort of those at $50 \%$ risk and follow participants from the age when they become eligible for predictive testing until they undergo predictive testing, have onset of symptoms or reach old age. This is clearly very costly and impractical.

Here, we propose a method to estimate the uptake of predictive testing. It requires the specification of three factors explained above:

(1) The number of people at $50 \%$ risk of $\mathrm{HD}$ at the beginning of the study period, which includes a deduction for those who have not yet reached the 'age of majority'.

(2) The cumulative number of people at $50 \%$ risk of HD over the period of the study.

(3) The duration of the study period.

The number at $50 \%$ risk who are eligible for predictive testing is typically calculated from the prevalence of symptomatic HD, using a 1:5 ratio, proposed by Conneally. ${ }^{2}$

One study finds this proposed ratio accurate, ${ }^{4}$ whereas our own data suggest it is an overestimate. Those aged less than the 'age of majority' are generally ineligible for predictive testing, so the calculated number who are at $50 \%$ risk should be reduced accordingly (the best estimate is $5.6 \%$ in Victoria).

All previous calculations of the uptake of predictive testing among those at 50\% risk have incorrectly used a static figure for the number of individuals at $50 \%$ risk of HD (the denominator in the uptake proportion). This denominator should include all people in the geographical region serviced by the predictive testing program who were eligible for predictive testing during the study period. The correct figure consists of the number of people at $50 \%$ risk who have reached the age of majority on the day the study begins (denoted ' $P$ ') plus the number who become eligible over the course of the study. One way to estimate the additional number of people who become eligible over the period of the study is to assume that each individual who was symptomatic at the start of the study period (and who therefore contributed five people who were at 50\% risk) and who dies is then 'replaced' in the population by another symptomatic individual, thus maintaining a steady population prevalence of symptomatic HD. The five people at $50 \%$ risk attributable to the deceased individual are joined in the total group at $50 \%$ risk by five new individuals because another person became symptomatic with HD who has 'replaced' the deceased individual.

We use a disease duration (from symptom onset to death) of 18.8 years, being the average of two figures (16.2 years and 21.4 years), which report median disease duration on large cohorts. ${ }^{14,15}$ We therefore estimate the cumulative number who have been at $50 \%$ risk of $\mathrm{HD}$ and eligible for predictive testing (denoted ' $\mathrm{D}$ ') as

$\mathrm{D}=P+(P \times$ study duration in years $) / 18.8$

Therefore, to calculate uptake, the following formula is applied:

Uptake $(\%)=($ number of predictive tests in the study period/D) $\times 100$.

\section{What is the uptake of predictive testing for HD in Victoria, Australia?}

For this calculation, we have used data from 1996 to 2003. We have chosen not to use data from 1994 to 1995, as there were a high number of tests related to the direct gene test being available for the first time. We have chosen not to include those who had predictive testing by linkage, as this was not available to all at $50 \%$ risk. The number of symptomatic individuals identified (see above) was 382 . Thus, the number at risk is $382 \times 5=1910$ (according to Conneally's formula) or $382 \times 4.2=1604$ (according to our empirical data of those at $50 \%$ risk per symptomatic individual). To calculate $P$, we deduct $5.6 \%$ to exclude those less than the age of majority. This is 1803 and 1514 individuals respectively.

The number of people who received predictive testing results and were at 50\% risk of HD from 1996 to 2003 ( 8 years) was 333 . Therefore, the uptake calculated using Conneally's formula for estimating the number at risk is:

$$
\begin{aligned}
& (333 / 1803+(1803 \times 8) / 18.8) \times 100 \\
& =333 / 2570 \times 100=13.0 \% .
\end{aligned}
$$

The uptake using our empirical data of the number at $50 \%$ risk is:

$$
\begin{aligned}
& (333 / 1514+(1514 \times 8) / 18.8) \times 100 \\
& =333 / 2158 \times 100=15.4 \% .
\end{aligned}
$$

As the numerator and denominator are both dynamic numbers over the same time period, the actual time period is corrected for.

\section{Discussion}

A method to assess uptake of predictive testing is of vital interest to clinicians and service providers and is a focus of numerous, major reports from testing centers (Table 1). Some commentators $^{16}$ have hypothesized regarding apparent differences in uptake between countries or regions. However, if the previously accepted calculation 
for uptake is inaccurate, we contend that such constructions could not be supported.

Our proposed uptake formula does not accommodate more sophisticated population dynamics such as immigration/emigration or a shift in demographic profile over time. Nevertheless, the results from this method of estimation fit much better with our clinical observations than uptake figures derived using the previously accepted method of calculation. Our proposed formula takes into account the fact that the number eligible for predictive testing is not static but rather a cumulative number that increases over time, as more people become at 50\% risk as a result of a parent becoming symptomatic with HD. This proposed formula, which accounts explicitly for the study duration, now allows for calculation and comparison of uptake across centers where a different period of testing is being reported.

\section{Acknowledgements}

We thank Pamela Marshall, Social Worker in Predictive Testing, Huntington Disease Service, Launceston General Hospital, whose astute clinical observations and concern about uptake calculations also prompted this paper; and for comment on the text. We also thank Mavis Tassicker for comment on statistical concepts. MB Delatycki is a National Health and Medical Research Council Practitioner Fellow.

\section{References}

1 Taylor SD: Demand for predictive genetic testing for Huntington's disease in Australia, 1987 to 1993. Med J Aust 1994; 161: 351, 354-355.

2 Conneally PM: Huntington disease: genetics and epidemiology. Am J Hum Genet 1984; 36: 506-526.

3 Laccone F, Engel U, Holinski-Feder E et al: DNA analysis of Huntington's disease: five years of experience in Germany, Austria, and Switzerland. Neurology 1999; 53: 801-806.
4 Maat-Kievit A, Vegter-van der Vlis M, Zoeteweij M, Losekoot $\mathrm{M}_{\text {, }}$ van Haeringen A, Roos R: Paradox of a better test for Huntington's disease. J Neurol Neurosurg Psychiatry 2000; 69: 579-583.

5 Harper PS, Lim C, Craufurd D: Ten years of presymptomatic testing for Huntington's disease: the experience of the UK Huntington's Disease Prediction Consortium. J Med Genet 2000; 37: $567-571$

6 Goizet C, Lesca G, Durr A: Presymptomatic testing in Huntington's disease and autosomal dominant cerebellar ataxias. Neurology 2002; 59: 1330-1336.

7 Creighton S, Almqvist EW, MacGregor D et al: Predictive, prenatal and diagnostic genetic testing for Huntington's disease: the experience in Canada from 1987 to 2000. Clin Genet 2003; 63: $462-475$.

8 Tibben A, Frets PG, van de Kamp JJ et al: Presymptomatic DNAtesting for Huntington disease: pretest attitudes and expectations of applicants and their partners in the Dutch program. Am J Med Genet 1993; 48: 10-16.

9 Bloch M, Fahy M, Fox S, Hayden MR: Predictive testing for Huntington disease: II. Demographic characteristics, life-style patterns, attitudes, and psychosocial assessments of the first fiftyone test candidates. Am J Med Genet 1989; 32: 217-224.

10 Trembath MK, Tassicker RJ, Collins VR, Mansie S, Sheffield LJ, Delatycki MB: Fifteen years of experience in predictive testing for Huntington disease at a single testing center in Victoria, Australia. Genet Med 2006; 8: 673-680.

11 Craufurd D, Dodge A, Kerzin-Storrar L, Harris R: Uptake of presymptomatic predictive testing for Huntington's disease. Lancet 1989; 2: 603-605.

12 International Huntington Association and the World Federation of Neurology Research Group on Huntington's Chorea: Guidelines for the molecular genetics predictive test in Huntington's disease. J Med Genet 1994; 31: 555-559.

13 Australian Bureau of Statistics. Demography Victoria: 3311.2, 2000. http://www.ausstats.abs.gov.au/Ausstats/subscriber.nsf/0/ 4F87599421188193CA256B250081F093/\$File/33112_2000.pdf.

14 Roos RA, Hermans J, Vegter-van der Vlis M et al: Duration of illness in Huntington's disease is not related to age at onset. J Neurol Neurosurg Psychiatry 1993; 56: 98-100.

15 Foroud T, Gray J, Ivashina J et al: Differences in duration of Huntington's disease based on age at onset. J Neurol Neurosurg Psychiatry 1999; 66: 52-56.

16 Hayden M: Predictive testing for Huntington's disease: a universal model? Lancet Neurology 2003; 2: 141-142. 